\title{
A Newborn Female with a Diffuse Rash
}

\author{
Zachary E. Holcomb ${ }^{a}$ Sherry H. Yu ${ }^{a} \quad$ Tyler D. Menge ${ }^{a}$ \\ Rosalynn M. Nazarian ${ }^{b}$ Chad J. Jessup ${ }^{c}$ \\ a Harvard Combined Dermatology Residency Program, Department of Dermatology, \\ Massachusetts General Hospital, Boston, MA, USA; ${ }^{b}$ Department of Pathology, \\ Massachusetts General Hospital, Boston, MA, USA; 'Department of Dermatology, \\ Brigham and Women's Hospital, Boston, MA, USA
}

\author{
Keywords \\ Langerhans cell histiocytosis $\cdot$ Neonatal period $\cdot$ Rash
}

\begin{abstract}
Langerhans cell histiocytosis is a rare and clinically heterogeneous group of dendritic histiocytic disorders with typical onset in the neonatal period or infancy, although it can present at any age. Histiocytes accumulate in one or more organs, leading to a variable clinical presentation of disease. We report a case of biopsy-proven Langerhans cell histiocytosis in a newborn and discuss the workup and management of this disease, along with reviewing its clinical variants.

(C) 2019 The Author(s)

Published by S. Karger AG, Basel
\end{abstract}

\section{Case Report}

A newborn girl was transferred to Massachusetts General Hospital at 1 day of age with a diffuse rash. She was born at 41 weeks' gestational age as the first child of a 27 -year-old mother. The mother had a history of genital herpes simplex virus and was treated with prophylactic acyclovir starting at 36 weeks' gestation. There were no active lesions at the time of delivery. The pregnancy and delivery were otherwise uncomplicated, and initial Apgar scores were 8 and 9 at 1 and $5 \mathrm{~min}$, respectively. The patient was feeding and voiding well and appeared healthy at the time of arrival to Massachusetts General Hospital.

A diffuse skin rash was first noted at the time of delivery. The patient had scattered erythematous and brown macules and thin papules on the face, head, trunk, and extremities, including acral sites (Fig. 1). Many of these lesions had overlying serous crusts and peripheral 

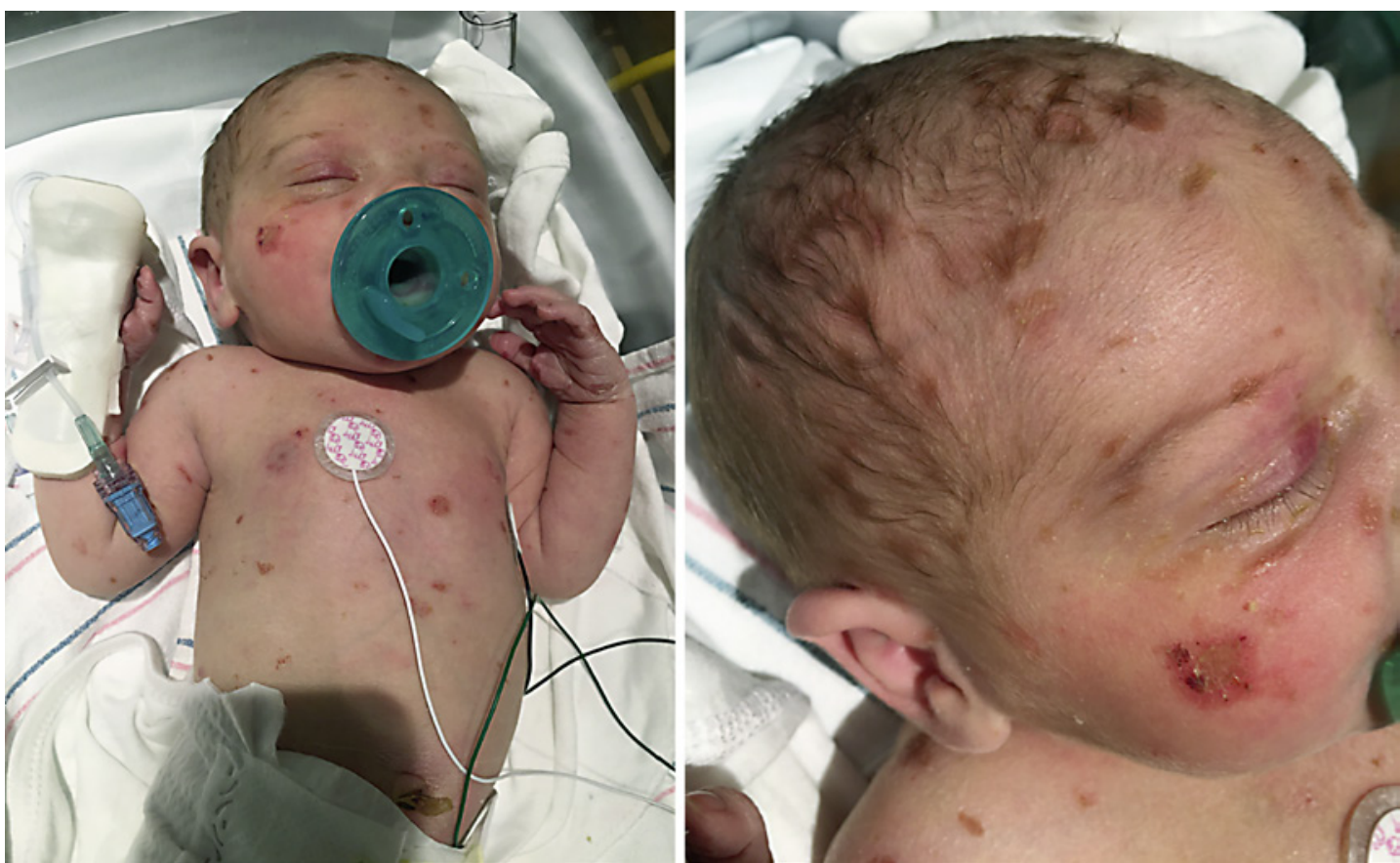

Fig. 1. Erythematous and brown macules and thin papules with overlying serous crust and peripheral scale scattered diffusely on the head, face, trunk, and extremities. Photos courtesy of Dr. Sherry Yu.

scale. An infectious workup was initially pursued, including a swab from one of these lesions for bacterial culture and herpes simplex virus culture, blood cultures, and a lumbar puncture with bacterial culture, fungal culture, herpes simplex virus polymerase chain reaction, and enterovirus polymerase chain reaction. These tests did not identify an infectious source.

\section{Diagnosis and Clinical Course}

The inpatient dermatology service was consulted and performed a skin punch biopsy of a representative lesion on the left calf. Histopathologic examination revealed a papillary dermal infiltrate composed predominantly of epithelioid cell aggregates with abundant eosinophilic cytoplasm and irregular reniform nuclei, consistent with Langerhans cells (Fig. 2). CD1a and Langerin immunohistochemical studies confirmed the presence of Langerhans cells (Fig. 2). BRAF V600E immunohistochemistry was negative. Tissue culture, mycobacterial culture, and fungal culture of the skin at the time of biopsy were all negative for growth of organisms. The histologic findings, in conjunction with the physical exam, were consistent with a diagnosis of Langerhans cell histiocytosis (LCH).

After the diagnosis of LCH was established, a workup for systemic involvement was undertaken. This included blood samples to evaluate complete blood counts, liver function tests, blood urea nitrogen, creatinine, electrolytes, and coagulation studies (prothrombin time and partial thromboplastin time). These values were all within the laboratory reference ranges for normal. Imaging studies to evaluate for systemic involvement included a chest radiograph, abdominal ultrasound, and skeletal radiograph survey, all of which revealed no evidence of systemic LCH involvement. The patient was discharged home at 4 days of age.

On outpatient follow-up at 14 days of age, the skin lesions were noted to be less prominent and fading compared to her prior examination in the hospital. The parents had been 


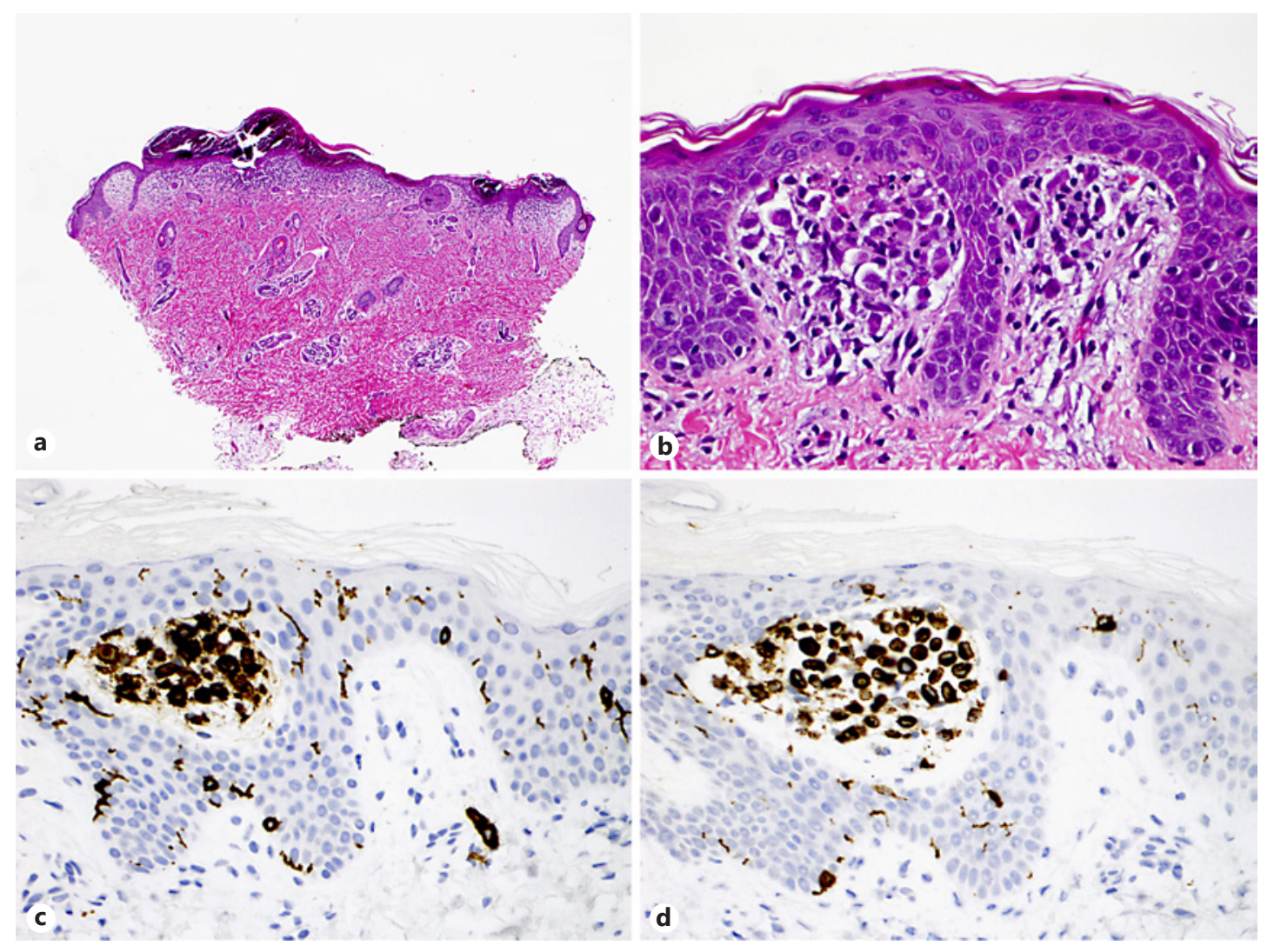

Fig. 2. a Histopathologic evaluation of the left calf skin biopsy reveals a diffuse papillary dermal infiltrate with overlying epidermal scale crust (hematoxylin and eosin, $\times 4$ objective magnification). b Higher power reveals the papillary dermal infiltrate to be composed predominantly of epithelioid cell aggregates with abundant eosinophilic cytoplasm and irregular reniform nuclei (hematoxylin and eosin, $\times 40$ ). c, d Immunohistochemical studies for CD1a and Langerin reveal strong positive staining in the epithelioid cells consistent with Langerhans cell histiocytosis (CD1a and Langerin stains, respectively, ×40).

applying topical petrolatum jelly to the affected areas daily, but no other therapeutic interventions were being performed. At her subsequent outpatient visit at 2 months of age, the skin lesions had completely resolved and she was developing normally.

\section{Discussion/Conclusion}

LCH is a rare histiocytic disorder involving a clonal proliferation of Langerhans cells. The clinical spectrum of LCH varies widely from single organ to multisystem involvement. Initially described in the early 20th century, the variants of LCH were thought to represent separate disease processes. These included an acute diffuse form (Letterer-Siwe disease) [1, 2], a triad of central nervous system involvement with diabetes insipidus accompanied with bone lesions and exophthalmos (Hand-Schüller-Christian disease) [3-5], and a localized form with largely asymptomatic granulomatous bone lesions (eosinophilic granuloma) [6, 7]. In the late 20th century, Hashimoto and Pritzker [8] described a fourth clinical entity, a self-resolving skin-limited eruption consisting of papulonodules and vesicles, which they termed "congenital self-healing reticulohistiocytosis." Following confirmation of the relationship of the patho- 
logic cells in all of these entities, they have now been grouped together by the Writing Group of the Histiocyte Society under the umbrella term "Langerhans cell histiocytoses" [9].

The incidence of LCH is low, with anywhere from 2 to 9 cases per million children per year reported [10]. The incidence of LCH peaks between 1 and 4 years of age worldwide, and there is a slight male predominance [11]. Adult onset can occur as well, but the incidence in adulthood is less frequent than in children, representing fewer than $30 \%$ of cases [12]. The actual incidence of LCH in both the pediatric and adult populations may be higher than reported due to frequent misdiagnosis and failure to recognize this rare condition.

The pathogenesis of LCH is debatable, but many regard the disease as a clonal neoplastic disorder of Langerhans cells representing misguided myeloid differentiation. Recently, the oncogenic BRAF V600E mutation was demonstrated in over half of LCH tissue specimens [13]. This mutation has previously been described in other malignancies, including papillary thyroid carcinoma and melanoma, further supporting the neoplastic pathogenesis of LCH. Notably, there appears to be a hereditary component as well, as familial cases have been reported [14].

One of the greatest challenges in diagnosing LCH arises due to the variability in clinical presentation. As mentioned previously, multiple variants have been described, and clinical features can range from indolent single organ involvement to devastating multisystem disease. Cutaneous lesions often present as small pink or skin-colored papules, pustules, or vesicles in a seborrheic distribution, as well as on the axilla and perineum. Scale and crust with secondary impetiginization are commonly seen. The cutaneous distribution of LCH commonly leads to misdiagnosis as seborrheic dermatitis, intertrigo, or diaper dermatitis. However, when these lesions fail to respond to conventional therapies for these alternative disease processes, the clinician should entertain the possibility of LCH in the differential diagnosis. Other primary morphologies are possible in cutaneous LCH as well, including the red to purple-brown papulonodules of the congenital self-healing reticulohistiocytosis variant, which leads to a broad differential diagnosis [15].

Multiple techniques exist to distinguish LCH from alternative diagnoses. A standardized approach to diagnosis and evaluation of extent of disease is mandatory for all patients with LCH to prognosticate and tailor treatment. This process begins with a thorough history and physical exam, which should focus on evaluation of the skin, lymph nodes, oral cavity, bones, lungs, thyroid, liver, central nervous system, and spleen. Skin biopsy demonstrating a Langerhans cell infiltrate with confirmatory immunohistochemical staining demonstrating S100 protein, CD1a, and/or Langerin (CD207) positivity clinches the diagnosis. Electron microscopy can be used to demonstrate the characteristic Birbeck granules within Langerhans cells, but because of the availability of CD1a and Langerin staining, immunohistochemical staining is currently the much more commonly employed technique.

Patients with a confirmed diagnosis of cutaneous LCH should undergo further evaluation for systemic involvement. Langerhans cells can infiltrate virtually any organ system in addition to the skin, but they often have a propensity for bone, the central nervous system, lungs, liver, lymph nodes, spleen, and the hematopoietic system [12]. Assessing for extent of systemic involvement therefore commonly includes both laboratory tests and imaging studies. At a minimum, most patients with confirmed LCH should have a complete blood count, liver function testing, electrolyte assessment, skeletal survey, chest radiography, and ultrasonography of the liver and spleen [15]. Additional laboratory testing and imaging depend upon the individual patient and should be directed at evaluation of any other signs and symptoms that may be present.

The treatment of LCH depends entirely on the degree and severity of involvement. For mild skin-limited disease, there is often spontaneous resolution, and therefore treatment typically involves either observation or topical agents [15]. Topical corticosteroids are 
considered first line, with alternative agents including topical nitrogen mustard, imiquimod, and phototherapy. Systemic therapy is only indicated in cutaneous-limited LCH for symptomatic or progressive disease. Multisystem disease, however, often requires systemic therapy. According to the Histiocyte Society Evaluation and Treatment Guidelines, systemic therapy is indicated if any of the following criteria are met: multisystem LCH, single-system LCH with multifocal bone lesions, single-system LCH with critical site lesions (certain craniofacial or vertebral bone lesions), or single-system LCH with at-risk central nervous system lesions [16]. The standard first-line therapy includes systemic corticosteroids with vinblastine for 1 year, with additional agents used for patients who relapse or do not respond to first-line therapy [15]. Because of the recent association of BRAF V600E mutations with LCH lesions, selective inhibitors of this protein, such as dabrafenib and vemurafenib, may play a role in future treatment algorithms as well.

The patient presented here displayed classic LCH lesions in a characteristic seborrheic and truncal distribution. Following histopathologic confirmation, systemic workup for extracutaneous manifestations was unrevealing. Skin-limited disease has an excellent prognosis and often completely resolves within months to years, which was the case for this patient by 2 months of age. This case highlights the importance of considering LCH in the differential diagnosis of diffuse cutaneous lesions in a newborn and also details the necessary systemic workup for these patients.

\section{Statement of Ethics}

The manuscript was prepared in compliance with all ethical and confidentiality guidelines and principles. The parents of the subject have provided their written informed consent for the publication of the case and images.

\section{Disclosure Statement}

The authors have no conflicts of interest to disclose.

\section{Author Contributions}

All of the listed authors participated in data acquisition/analysis, drafted or revised the manuscript, and approved the final version. All authors attest to the accuracy of this submission and agree to be accountable for all aspects of the work.

\section{References}

1 Letterer E. Aleukämische Retikulose (Ein Beitrag zu den proliferativen Erkrankungen des Retikuloendothelialen Apparates). Frankf Z Pathol. 1924;30:377-394.

2 Siwe SA. Die Reitikuloendotheliose - ein neues Krankheitsbild unter den Hepatosphlenomegalien. Eur J Pediatr. 1933;55:212-47.

3 Christian H. Defect of membranous bones, exophthalmos and diabetes insipidus: an unusual syndrome of dyspituitarism. Med Clin North Am. 1920;3:849-71.

4 Hand A. Defects of Membranous Bones, Exophthalmos and Polyuria in Childhood: Is It Dyspituitarism? Am J Med Sci (1827-1924). 1921;162:509.

5 Schüller A. Über eigenartige Schädeldefekte im Jugendalter. Fortschr Rontgenstr. 1915/16;23:12-8. 
6 Lichtenstein L, Jeffe HL. Eosinophilic granuloma of bone: with report of a case. Am J Pathol. 1940 Sep;16(5): 595.

7 Otani S, Ehrlich JC. Solitary granuloma of bone: simulating primary neoplasm. Am J Pathol. 1940 Jul;16(4):479.

8 Hashimoto K, Pritzker MS. Electron microscopic study of reticulohistiocytoma. An unusual case of congenital, self-healing reticulohistiocytosis. Arch Dermatol. 1973 Feb;107(2):263-70.

9 Chu T, d'Angio G, Favara B, Ladisch S, Nesbit M, Pritchard J; Writing Group of the Histiocyte Society. Histiocytosis syndromes in children. Lancet. 1987 Jan;1(8526):208-9.

10 Poompuen S, Chaiyarit J, Techasatian L. Diverse cutaneous manifestation of Langerhans cell histiocytosis: a 10-year retrospective cohort study. Eur J Pediatr. 2019 May;178(5):771-6.

11 Yağci B, Varan A, Cağlar M, Söylemezoğlu F, Sungur A, Orhan D, et al. Langerhans cell histiocytosis: retrospective analysis of 217 cases in a single center. Pediatr Hematol Oncol. 2008 Jun;25(5):399-408.

12 Allen CE, Merad M, McClain KL. Langerhans-Cell Histiocytosis. N Engl J Med. 2018 Aug;379(9):856-68.

13 Badalian-Very G, Vergilio JA, Degar BA, MacConaill LE, Brandner B, Calicchio ML, et al. Recurrent BRAF mutations in Langerhans cell histiocytosis. Blood. 2010 Sep;116(11):1919-23.

14 Aricò M, Nichols K, Whitlock JA, Arceci R, Haupt R, Mittler U, et al. Familial clustering of Langerhans cell histiocytosis. Br J Haematol. 1999 Dec;107(4):883-8.

15 Krooks J, Minkov M, Weatherall AG. Langerhans cell histiocytosis in children: Diagnosis, differential diagnosis, treatment, sequelae, and standardized follow-up. J Am Acad Dermatol. 2018 Jun;78(6):1047-56.

16 Satter EK, High WA. Langerhans cell histiocytosis: a review of the current recommendations of the Histiocyte Society. Pediatr Dermatol. 2008 May-Jun;25(3):291-5. 